\title{
5 Using evaluations to inform policy and practice in a government department
}

\author{
The case of the Department of \\ Basic Education in South Africa
}

\author{
Nedson Pophiwa, Carol Nuga Deliwe, \\ Jabulani Mathe and Stephen Taylor
}

\section{Summary}

South Africa's education sector has been very problematic with educational outcomes being less than desired. It has had to overcome the legacy of apartheid, and has struggled to create an effective educational system. The Department of Basic Education has been a pioneer department in the use of evaluations, research and data. Two of eight evaluations undertaken by the department are used as mini-cases of the use of evaluations: the Funza Lushaka Bursary Programme and the National School Nutrition Programme. A variety of instrumental, conceptual and process uses of the evaluations can be seen, supported by a range of use interventions undertaken internally by the department, supported through the mechanisms of the national evaluation system. The cases provide examples of evidence-informed policy and practice and how a government department can undertake evaluations effectively. They demonstrate the importance of an internal knowledge broker who is involved in the strategic discussions to champion and support evidence, as well as the usefulness of a national evaluation system providing key elements that encourage use.

\section{Background}

In 1994 the new government, led by the African National Congress, was faced with overcoming the legacy of discriminatory apartheid policies that deliberately provided poor quality education to black people.

The quality of basic education in South Africa has been a government priority since the advent of democracy in 1994. The new Department of Education (DoE) began crafting policy to transform, seek redress, and enable equity and quality education outcomes for all South Africans. Most people have participated in or experienced the education system and have strong views on the system's deficiencies and how to improve it. Tackling problems has required juggling popular ideas with scientific and evidence-informed approaches.

In 2010, the DoE was reorganised into two departments, the Department of Basic Education (DBE) and the Department of Higher Education and Training (DHET), 
to focus on the schooling and post-schooling sectors, respectively.The DBE is one of the stakeholders involved in establishing South Africa's national evaluation system (NES), and a pioneer in using evidence for policy and decision making.

This chapter examines the DBE's journey and looks at two mini-cases of the use of evaluations, the Funza Lushaka Bursary Programme (FLBP) for teachers, and the National School Nutrition Programme (NSNP), which were selected based on the importance of the programmes and the DBE's intention to use the products and outcomes of the evaluations in strengthening policy support and implementation. The chapter sets out lessons for the use of evaluations, and the factors enabling or hindering it in the DBE.

The methodology was guided by an analytical framework in Chapter 3 that informed the selection of research questions. Data collection methods included the review of published and unpublished documents such as annual reports, peer-reviewed journal articles, and evaluation reports. Semi-structured interviews were conducted between November 2018 and March 2019 with seven DBE officials, both senior policy makers, focusing on those managing the programmes in the two cases chosen (NSNP and FLBP), as well as monitoring and evaluation (M\&E) officials from DBE and the Department of Planning, Monitoring and Evaluation (DPME).The involvement of key players in the process as co-authors provided the richness of participant observation. The chapter was drafted by a researcher, with key historical, structural and substantive contributions from the co-authors in DBE and DPME.

\section{Overview of the sector and its evidence journey}

\section{Country context}

South Africa is a constitutional democracy with a three-tier system of government: national, provincial and local. Education is shared between the national and provincial levels, with provincial having the responsibility for running the school system and national responsible for policy and functions such as teacher training and universities. There have been four education ministers since 1994, each bringing significant changes (Motala, 2015). The incumbent, Minister Motshekga, who has been in post since 2009, had oversight of the creation of the DBE and DHET from the original DoE.

South Africa's school education successes have been in providing universal access to educational opportunities for the majority of learners (97\% participation for 7 - to 15 -year-olds, and $83 \%$ for 16- to 18 -year olds); improving infrastructure; equalising resource allocation; providing free education to learners from poor households; and expanding the nutrition programme to about nine million learners (DBE, 2018b).

Despite South Africa's middle-income status and a large proportion of government spending on education, the major shortcoming is the quality of education outcomes, which can be seen in relation to our Southern African Development Community (SADC) neighbours. The main contributory factors to these deficiencies include: the lasting effects of intergenerational poverty; 
low levels of language and cognitive skills of learners coming into the system; structural and accountability weaknesses in teaching, management and school support at district level; and low efficiency of conversion of resources into quality in government. Attempts to address school education challenges have been characterised by blame and a lack of accountability (National Planning Commission (NPC), 2012, p. 302). Despite a history of poor learning outcomes and performance, recent regional and international assessments for learners from poor households have shown improvements in education outcomes and quality in the foundation phases of schooling, albeit off a low base (Reddy et al., 2016).

\section{The development of structures to use evidence in DBE}

The DBE has a long tradition of using statistical evidence drawn from administrative data, official statistics on the population and special surveys. The educational planning system was developed from a need to understand the size and shape of the education system, and the first forays into evidence use were drawn from the first Schools Register of Needs, commissioned in 1996 to provide planning information on the distribution of resources and the extent of backlogs that the new government had to deal with. An Education Management Information System was created in 2001 to collect information on school-level resourcing, complementing information in the personnel administration system, followed by creation of a small Policy Support Unit to support system-wide planning, monitoring and evaluation and track medium- to long-range performance.

The Policy Support Unit set out to supplement the administrative data in the schooling system by motivating and advocating for education policy-relevant data in existing data collection, including those undertaken by Statistics South Africa. This allowed trends in provisioning of educational inputs, as captured in household surveys, to be analysed with provincial disaggregations from 2002 onwards. Deeper analysis was done of education data collected in demographic data. In its first decade, the unit focused on generating policy-relevant analyses and trends using in-house data and specially commissioned surveys. Econometric and other analyses of school performance were also possible using the end of school Grade $12^{1}$ Senior Certificate Examination performance data and panel data provided by the National School Effectiveness Survey that was carried out over three years from 2007. This confirmed how little learning was happening in schools, even in the lower grades.

By 2010, the Policy Support Unit had been clustered with the unit responsible for short- to medium-term planning and monitoring and renamed the Research Coordination, Monitoring and Evaluation (RCME) Unit in the Strategic Planning, Research and Coordination Chief Directorate, with the former policy support director as head of the Chief Directorate. The new unit retained the functions of the Policy Support Unit and was now also responsible for intergovernmental coordination, strategic planning, research coordination, monitoring and evaluation. Its briefings, reports and analyses on policy-relevant trends were adopted in policy circles. Presentations by the director general and senior managers to oversight bodies and stakeholders increasingly included 
reference to data and trends rather than a recital of expenditure patterns, programme delivery and monitoring visits. Resolutions at ruling party conferences began to refer to this information.

By 2010, despite contestation around their use, national and international assessments of learning outcomes were used to identify the factors associated with the low levels of performance in schools. Between 2011 and 2014,Annual National Assessments (ANA) were implemented to measure learning outcomes at school level in maths and language from Grades 1 to 9. These created pressure for schools to account for learning performance and indicated what was expected in terms of learning outcomes at each grade. However, the assessments were abandoned in 2015 as burdensome, too frequent, and too focused on reporting and naming and shaming. ${ }^{2}$ By 2018 , despite the abrupt end of the ANA, long-standing participation in these assessments had illustrated progress in learning outcomes, albeit from a low base.

Despite resistance by unions, the tradition of tracking performance in the schooling system using evidence from different sources was strong and provided fertile ground for adopting an evaluative approach in policy analysis. By 2012, the National Development Plan (NDP) had been launched. The Basic Education Sector plan (developed in 2010) informed the education chapter of the NDP, along with a diagnostic review of the barriers to effective schooling and quality learning, and interventions designed to improve the quality of learning (NPC, 2011, 2012).

A textbook availability crisis in 2012 resulted in criticism of the political and administrative leadership of the national department and the minister responsible.The trauma of the crisis was felt in the whole system. There was heightened public and media scrutiny of the roles and responsibilities of provincial and national departments in service delivery, the monitoring systems and the data required to monitor progress. Information from household surveys was perceived by political and union-aligned stakeholders and the public as more independent than the education sector's administrative data, and so more credible.

The crisis was a turning point in the schooling system and galvanised the national and provincial departments responsible for basic education to work with experts to develop and document national standards and a national system for improving process management, capacity and monitoring of textbook provisioning, delivery and management.

Changes in the South African government-wide approaches to monitoring and evaluation were also critical in supporting DBE's momentum. A National Evaluation Policy Framework (NEPF) was approved by Cabinet in November 2011, with experts from DBE as co-authors (Davids et al., 2015, p. 1; Phillips et al., 2014). In its efforts to build a coalition to support the evaluation system, DPME established a cross-government Evaluation Technical Working Group (ETWG) 'as a sounding board and to be an advocate of the system' (Goldman et al., 2015, p. 3). DBE was among the early adopters and members of this ETWG as they had already undertaken evaluations.

Following adoption of the NEPF, in 2012 the national evaluation system (NES) was being designed. However, the harrowing and very public events of the textbook 
crisis in 2012 were fresh in the minds of policy makers and the context of implementing evaluations in the schooling system was politically charged. Too critical or public, and unfavourable evaluation findings could be shelved and not used. Too positive, and the media could dismiss the work as propaganda in a country with a healthy cynicism about service delivery. Faced with coordinating evaluations in the sector, the concerns in the DBE's evaluation unit were not only technical.

The unit adopted an improvement support approach, providing technical support and closely partnering the evaluating programme managers, with support from DPME. The M\&E unit communicated the utility of evaluations in improving programme quality, effectiveness and efficiency. Drawing from the events that followed the textbook crisis, this improvement narrative resonated with programme managers and was used during and after the evaluation in discussions and debates, as well as in strategic events and presentations.

A range of programmes was identified for evaluation, with all programmes selected receiving large amounts of funding, ranging from early childhood development programmes to nutrition, initial teacher education bursaries, and the best ways of teaching reading. Six of the eight evaluations were implementation evaluations, partly because impact could not be determined due to the lack of data.

The NES required a number of systems to be established including Evaluation Steering Committees (ESCs), which included the custodian department and DPME, a commitment to publishing the evaluations as a deliberate accountability mechanism, development of a management response and implementation of improvement planning, with reports on progress for two years following approval of the report.

\section{Starting evaluations under the national evaluation system}

Prior to 2011, 'monitoring and evaluation' activities in DBE and its precursor had to a large extent been limited to monitoring and standard forms of reporting (Samuels et al., 2015, p. 3). Table 5.1 provides a list of the research and evaluations carried out from 2011. The first evaluation under the NES was of Early Childhood Development (ECD), undertaken with the Departments of Social Development and Basic Education and Health. This evaluation, reported in 2012, recommended that further evaluations should be undertaken on two components of ECD, namely an additional reception year of schooling (Grade R) and on nutrition interventions for children under five. In 2012/2013, an impact evaluation of the introduction of Grade $\mathrm{R}$ was carried out by a team of researchers from Stellenbosch University, building on the relatively good data that DBE had on learning outcomes from ANAs, and administrative data on registrations for Grade R.

With the stopping of ANA due to contestation from the main teacher union, DBE no longer had good data on learning outcomes and focused instead on implementation or impact evaluations of large programmes. The data was used to generate lessons to assist programme managers to improve their programmes. 
Nedson Pophiwa et al.

Table 5.1 List of DBE's research and evaluations to date

\begin{tabular}{|c|c|c|}
\hline Name & Type/purpose & Year \\
\hline School Monitoring Survey & $\begin{array}{l}\text { Survey of sector progress in achieving } \\
\text { education mandate }\end{array}$ & $2011 / 2012$ \\
\hline $\begin{array}{l}\text { Independent Workbook and } \\
\text { Textbook Evaluation }\end{array}$ & $\begin{array}{l}\text { Formative evaluation of a sample of approved } \\
\text { DBE workbooks and textbooks }\end{array}$ & $2011 / 2012$ \\
\hline $\begin{array}{l}\text { The Impact of the } \\
\text { Introduction of Grade } R^{\star}\end{array}$ & $\begin{array}{l}\text { Evaluation to estimate the effect of having } \\
\text { attended Grade R on learning outcomes } \\
\text { later in primary school }\end{array}$ & $2012 / 2013$ \\
\hline $\begin{array}{l}\text { The Mind the Gap Impact } \\
\text { Assessment }\end{array}$ & $\begin{array}{l}\text { Randomised Control Trial to measure impact } \\
\text { of study guides on performance }\end{array}$ & $2012 / 2013$ \\
\hline $\begin{array}{l}\text { The Funza Lushaka Bursary } \\
\text { Programme` }\end{array}$ & $\begin{array}{l}\text { Implementation evaluation of FLBP } \\
\text { Programme }\end{array}$ & 2014-2016 \\
\hline $\begin{array}{l}\text { The Early Grade Reading } \\
\text { Study I North West }\end{array}$ & $\begin{array}{l}\text { Impact evaluation of three alternative teacher } \\
\text { training interventions in Setswana using a } \\
\text { randomised controlled trial method }\end{array}$ & 2015-2018 \\
\hline 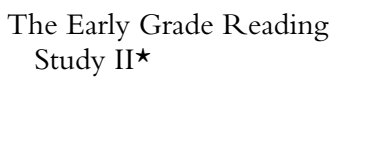 & $\begin{array}{l}\text { Impact evaluation of two alternative teacher } \\
\text { training interventions in English First } \\
\text { Additional Language using a randomised } \\
\text { controlled trial method }\end{array}$ & $\begin{array}{l}2016-2018 \\
(2015 \text { prep) }\end{array}$ \\
\hline CAPS $\star$ & $\begin{array}{l}\text { Implementation evaluation of the } \\
\text { Curriculum Assessment Policy Statement } \\
\text { (CAPS) system }\end{array}$ & 2015-2017 \\
\hline NSNP* & $\begin{array}{l}\text { Implementation evaluation of the National } \\
\text { School Nutrition Programme (NSNP) }\end{array}$ & 2014-2016 \\
\hline
\end{tabular}

Note: ${ }^{\star}$ Those in the National Evaluation Plan.

Evaluation buy-in was critical and the idea of improving implementation through evaluation was attractive for policy and practical purposes (Respondent 4). Once programme managers agreed to evaluations being conducted, it became easier for DBE to work with DPME to take evaluations forward.

Two evaluations are scrutinised in some detail in this chapter, both implemented as part of the National Evaluation Plan, and so in partnership with DPME. The chapter also mentions other evaluations and evidence that help to understand the contextual, institutional and cultural enablers or barriers to use of evidence in the educational policy space.

\section{The evaluation of Funza Lushaka Bursary Programme (FLBP)}

The FLBP was established in 2007 and provides full-cost bursaries to highachieving students to undertake initial teacher education (ITE) programmes to become teachers in priority subjects such as maths, physical science and accounting and in foundation phase learning, and locations such as rural areas. It is a large-scale programme that reached 23,392 students during the period under evaluation (2007-2012), on average 15\% of the total ITE enrolment over the period (DPME/DBE, 2016b). Owing to the importance of the programme and the need to motivate for its continued support by government, the head of the 
unit responsible for planning, monitoring, evaluation and research managed to convince key officials responsible for it to use the evaluation as an opportunity to improve implementation.

It was decided that the evaluation would be an implementation evaluation rather than an impact evaluation. The evaluation was procured by DPME and JET Educational Services was contracted to conduct it.

The overall findings were that the FLBP is performing well and is broadly effective (and cost-effective) in attracting high-achieving students who complete ITE programmes in good time and take up government-paid positions in public schools (DPME/DBE, 2016b). However, the evaluation identified inefficiencies in implementation with regard to supply and placement of educators at different levels of government. The final report, management response, and improvement plan to address the findings were approved by Cabinet in March 2017.

The improvement plan has been taken forward. 'The programme manager agreed with the recommendations and so he was eager to see those things put in place. In some of the other programmes it was more of a burden to be seen to be implementing the improvement plan' (Respondent 1).

There are different ways of understanding evidence use, and here we consider instrumental, conceptual, symbolic and process use as used by Johnson et al. (2009) and Patton (1998). This differentiation was discussed in Chapter 1.

In terms of use of the findings and recommendations, a key area was rethinking the selection criteria to target specific areas of teacher specialisation. Prior to the evaluation, students were simply told 'if you want to be a teacher, we will give you a bursary' (Respondent 2). The evaluation report recommended that DBE, with universities, should develop an effective system to monitor the priority areas that students have enrolled for and that subject areas should be fixed between application and selection (DPME/DBE, 2016a, p. 36). Since then, they have produced a set of guidelines and criteria for selection of students based on geographic and subject area and phases required by the FLBP policy, and become stricter as to who is selected as a beneficiary (instrumental use).

The ITE Directorate was able to use recommendations related to monitoring, tracking and data management to motivate for funding to modernise the information management system and successfully approached government for funding an online system that has been in use since October 2018 and has been an important building block to effectively managing information concerning the programme (Respondent 2) (instrumental use).

The evaluation recommended that the DBE, in collaboration with provincial education departments (PEDs), needs to strengthen methods for effective placement of graduating students. The ITE directorate has begun reporting not on administration of placement but on the utilisation of graduates in terms of where they are placed upon completion (Respondent 2) (instrumental use).

The process of undertaking the evaluation was very important in itself (process use) and led to considerable learning. For example, the theory of change workshop brought together officials from higher education institutions, the National Student Financial Aid Scheme (NSFAS), civil society groups, and provincial and national department officials to gain an understanding of key 
components of the bursary programme (conceptual use). This was an eyeopener for Respondent 2 because it was the first time he saw stakeholders with a common interest in implementation of the bursary programme come together to deliberate constructively on it.

Another example was the building of successful relationships. In October 2018, DBE held an indaba to open a dialogue on teacher professionalisation, teacher standards and school-based initial teacher education models. The success of this event was attributed to the collaborative nature of the Funza Lushaka evaluation: 'it wouldn't have happened smoothly if we hadn't collaborated in the Funza evaluation' (Respondent 2). Relationships that were established during the evaluation, especially the theory of change workshop, are said to have been a critical enabler for this event (DBE, 2018a) (process use).

There are examples of unintended use. Parliament became more interested in understanding how FLBP graduates are placed in specific targeted areas rather than the logistical, administrative data concerning how placement was managed (Respondent 2). The Directorate responsible for FLBP negotiated a partnership framework with roles and responsibilities/activities at all levels of government. The Directorate also used the findings on placement to obtain independent external advice on how the unit could improve its own efficiency, for example, a contract on how quickly graduates should be placed.

\section{The evaluation of the National School Nutrition Programme}

In a country with high levels of poverty and inequality such as South Africa where many children go to school without breakfast, the NSNP aims to improve the health and nutritional status of the poorest learners. It was initially a Primary School Nutrition Programme (PSNP) administered by the Department of Health, which provided learners at primary schools with at least one meal per day. In 2002 it was decided that the programme should be migrated from the Department of Health to the Department of Education and expanded to cover beyond Grade 7.

Following a 2006 survey, the need to expand the programme to secondary schools was confirmed. Quintile 5 are the best-off public schools and quintile 1 the poorest. The renamed National School Nutrition Programme was first implemented in quintile 1 secondary schools in April 2009, and was phased in to quintile 2 and 3 public secondary schools in April 2010 and 2011, respectively (NSNP Annual Report, 2009). NSNP has involved a large financial commitment from government (ZAR 5.3 billion by 2014) and reaches over nine million learners. Apart from feeding children at school, NSNP includes campaigns raising awareness on healthy eating and lifestyles among learners.

In thinking about the type of evaluation to assess the NSNP, DBE/DPME commissioned a scoping study in 2012 that revealed insufficient data for the impact to be assessed. The Steering Committee of the evaluation decided to shelve the idea of an impact evaluation. However, in 2014 Cabinet requested the DBE to undertake an evaluation of the NSNP. It was agreed to resuscitate the evaluation as an implementation evaluation, achievable with the information 
at hand. The evaluation was commissioned by the DPME and DBE and was conducted by JET Education Services.

The main purpose of the evaluation was to assess whether the NSNP is being implemented in a way that is likely to result in significant health and educational benefits to primary school learners and establish how to improve programme effectiveness. The evaluation report was approved in October 2016.

In the management response, the DBE agreed with $80 \%$ of the recommendations and indicated that some are already being implemented (DPME, 2017, p. 19). An improvement plan was developed and the report and improvement plan were approved by Cabinet.

The programme managers have continued to implement the improvement plan and report on progress. The NSNP evaluation was used instrumentally in effecting changes directly to the roll-out of the school nutrition programme. There also appears to be good buy-in from the PEDs to implement the recommendations, which 'is evidence that the evaluation study has strong potential to shape and influence implementation of the NSNP in the near future' (DPME, 2017, p. 19).

The recommendations included introducing individual targeting in certain provinces/schools in which not all learners eat the NSNP meals regularly, and income and poverty levels are mixed. Task teams have been set up with their de facto terms of reference the NSNP evaluation recommendations relevant to the theme of the task team (Personal communication, Ms K. Maroba, Department of Basic Education, 8 October 2019). One task team, set up to determine the targeting criteria to be used in addressing learner opt-outs, recommended that there should be set criteria for targeting meals provision according to learner needs as long as it is affordable (Respondent 4) (instrumental use).

A recommendation was that the NSNP guidelines should specify who the meals are intended for, how leftover meals and stock should be dealt with, with monitoring of implementation. The guidelines indicate that if the meals are intended to encourage social cohesion and be eaten together by learners, volunteer food handlers, teaching and administrative staff, the guidelines should indicate this and concomitant funding be made available. Within the improvement plan, DBE committed to revising its guidelines on meals and developing stock control and plans to manage learner food preferences, leftovers and wasted food. For example, the DBE had been required to make a submission to National Treasury for approval of soya from predetermined manufacturers through the centralised procurement system. In response, the DBE evaluated the quality of soya mince and developed a list of compliant manufacturers, which was then approved and circulated to PEDs at the end of 2017 to guide procurement decisions (instrumental use).

In addition, the Department set up a menu task team to consider alternatives to soya as a protein in meals, in consultation with nutrition experts. Finally, the DPME's Quality Assessment Report emphasised that the evaluation process deepened stakeholders' understanding of the NSNP activities, opportunities for better implementation, and utility (DPME, 2017, p. 19) (conceptual use).

The evaluation provided the DBE with a robust understanding of successes, barriers and inefficiencies in implementing the programme, and an 
overview of the perceptions, concerns and successes in its implementation. This information confirmed and strengthened the policy makers' hand in putting forward a plan of action for the NSNP long after the improvement planning and reporting process had expired.

\section{Some conclusions on use}

In both evaluations we see considerable levels of use, including the different types we are focusing on. In one of the planning workshops that shaped the focus of this chapter, one comment that stood out was that DBE is among the few departments to have 'institutionalised the use of evidence' generated from research and evaluations.

\section{Use interventions undertaken and the change mechanisms}

Key for this book is understanding how evidence use happened and the interventions undertaken to promote use. Table 5.2 summarises and elaborates on some of these, including those undertaken through DBE systems, and features of the NES that assisted in ensuring use.

Overall we can see that the Chief Directorate responsible for Planning, Research, Monitoring and Evaluation played a key role in championing the use of evaluations and in knowledge brokering with programme managers, senior management of DBE, DPME and the evaluation service provider. This complemented the technical work done by the Monitoring and Evaluation Unit. In general the work produced by the research and evaluation directorate has been taken more seriously over the years. There is a recognisable shift in the attitude of senior management, which acknowledges the importance of the evidence they are generating and using.

Different forums were important in widening awareness and ownership of the evaluation.

Some of the meetings with senior people. ... when I present they often rush, they have a massive agenda. They try to finish within a day. When you sit to present they say please try to summarise in five minutes. But recently they have been asking for more, I had lots of time. I was presenting in parliament yesterday. There is more of an interest in that kind of work on improving, what the research is saying. That's quite encouraging to see.

(Respondent 1)

Ideally, organisations undertake evaluations at critical stages in the life cycle of interventions when important decisions need to be taken. Timing of the evaluation is therefore critical to facilitate use, while delays in finalising evaluations may prove to be a challenge as findings may be too late to incorporate findings during policy and programme reviews. Notwithstanding some delays, most recommendations from the two evaluations were still relevant for immediate use at the completion of the evaluation processes.

Three-quarters of all evaluation recommendations in basic education since 2013 have focused on promoting better internal operations rather than additional 
Table 5.2 Use interventions and how these influenced use

\begin{tabular}{|c|c|}
\hline Intervention & Effect and change mechanism activated \\
\hline \multicolumn{2}{|l|}{ DBE systems } \\
\hline $\begin{array}{l}\text { Knowledge brokering role } \\
\text { of Strategic Planning, } \\
\text { Research and Coordination } \\
\text { Chief Directorate }\end{array}$ & $\begin{array}{l}\text { The unit 'marketed' itself to programme managers to } \\
\text { help them see the value of improving implementation } \\
\text { through evaluations, and identifying possible topics. } \\
\text { It undertook internal communication to inform } \\
\text { management and minister of the findings and } \\
\text { recommendations } \\
\text { Working with programme managers helped to build } \\
\text { awareness in the Department of evaluations and } \\
\text { findings, trust in the credibility of findings, and to } \\
\text { ensure the institutionalisation of mechanisms to respond } \\
\text { to the evaluation }\end{array}$ \\
\hline $\begin{array}{l}\text { Unit having technically strong } \\
\text { members }\end{array}$ & $\begin{array}{l}\text { This allowed DBE to play a strong role in the technical } \\
\text { side of the evaluation, and increased the credibility } \\
\text { and legitimacy of it within DBE, and so trust in the } \\
\text { findings }\end{array}$ \\
\hline $\begin{array}{l}\text { Presenting and showcasing } \\
\text { evaluation findings in } \\
\text { different forums }\end{array}$ & $\begin{array}{l}\text { The evaluations were presented at the Council of } \\
\text { Education ministers, HeadCom of technical heads } \\
\text { of education departments in provinces with national } \\
\text { government, various interprovincial subcommittees, } \\
\text { e.g. on teacher development; curriculum; planning } \\
\text { and M\&E. This helped to build trust in the evaluation } \\
\text { results }\end{array}$ \\
\hline
\end{tabular}

\section{Elements of NES}

Technical Working Group and Evaluation Steering Committee

Developing theory of change with stakeholders

Validation workship with stakeholders

Simple evaluation report

Management response
TWG and ESC enabled co-development of all stages of the evaluation from formulation to finalisation. This facilitated agreement, ownership and trust between DPME and DBE and conviction in the usefulness of evaluation results

Helped to build common understanding of how the programme worked, valuable in itself, and interest by stakeholders in being part of the process

This made stakeholders aware of the findings and then recommendations were developed in an interactive manner with them. This allowed stakeholders an opportunity to reflect on the recommendations and thereby agree and own them, and trust the results

Improved accessibility helped with advocacy and dissemination of findings

The management response provided a formal mechanism whereby different departments had to acknowledge the recommendations and indicate those they agreed/disagreed with and why. It provided a way of institutionalising them 
Table 5.2 (Continued)

\begin{tabular}{|c|c|}
\hline Intervention & Effect and change mechanism activated \\
\hline Improvement plan & $\begin{array}{l}\text { This was developed for both evaluations and } \\
\text { implemented closely with FLBP and NSNP. It also } \\
\text { provided a formal mechanism for agreeing how to take } \\
\text { forward and institutionalise recommendations }\end{array}$ \\
\hline Quality assessment & $\begin{array}{l}\text { Both evaluations were checked by the DPME through } \\
\text { assessment of government evaluation reports to ensure } \\
\text { credibility and trust in evaluation findings }\end{array}$ \\
\hline $\begin{array}{l}\text { Report public on DPME } \\
\text { website }\end{array}$ & $\begin{array}{l}\text { Once approved by Cabinet the reports were made } \\
\text { available to the wider public on DBE and DPME } \\
\text { websites. This helped in giving stakeholders access to } \\
\text { the information, and awareness of the results }\end{array}$ \\
\hline Approval by Cabinet & $\begin{array}{l}\text { The Cabinet process was effective in getting people to } \\
\text { take the evaluation results seriously and in generating } \\
\text { momentum for follow-up actions. It also promoted } \\
\text { agreement by Cabinet and ownership of the results }\end{array}$ \\
\hline $\begin{array}{l}\text { Role of DPME evaluation } \\
\text { director }\end{array}$ & $\begin{array}{l}\text { Provided technical assistance, guidance and logistical } \\
\text { support for processes involved in evaluations, and a } \\
\text { bridge to reporting to Cabinet }\end{array}$ \\
\hline
\end{tabular}

resources. In general, the evaluations completed in DBE, far from being compliance exercises, have been used for operational improvement and policy review.

\section{The contextual factors supporting or hindering the use of evidence}

\section{Factors enabling use}

Table 5.1 shows the increase in research and evaluations commissioned by the department in recent years, which reflects the political will to support independent evaluation, information and data. The minister has over the years demonstrated an appreciation for the need to use evidence in planning and policy making. The length of her tenure has ensured stability in the leadership of DBE as the macro-departmental focus has remained the same. This has allowed sufficient time for the department to implement policy changes over time, unlike during the frequent changes in minister prior to 2009. Another critical aspect that was mentioned in the interviews was that it is not only political will at the level of the minister or Director General (DG) that matters but also the backing of project managers in the DBE. Project and programme managers who buy in to evaluations and use of evidence can commit resources and energy towards the realisation of activities outlined by the evaluation recommendations. They can even lobby the department to shift its approach towards a specific aspect as a result of lessons they have learned from an evaluation.

Crises related to delivery of educational services, such as the 2012 textbook crisis, provided the impulse for the department to be prepared to consider changes. This crisis threw into relief the need for integrated information for monitoring and evaluation in the sector. 
The Chief Directorate: Strategic Planning, Research and Coordination, which includes the Research and Evaluations Directorate, have been champions for evidence generation and use in DBE. They have played an important role in helping their peers who manage programmes and projects to appreciate the value of lessons from evaluations. They have access to strategic discussions in DBE and also provide a technically strong partner for DPME to work with on the evaluations, and they have played the knowledge broker role in DBE to maximise the likelihood of use.

It's a bit fragile in that it's still a bit dependant on personalities... . There are two or three very competent staff members in the directorate who have a good understanding of evaluations. I guess with them that's a move slightly towards institutionalisation (as) those types of people would hopefully be retained in the Department, and may move to management over time. . . part of our story has been the champions ... . without having to be pressurised into it or upskilled by DPME... . So it was fertile ground for the DPME to come and work in. But also maybe some of the juniors who are there now may become more senior in time. That's maybe a move in a direction of institutionalisation.

(Respondent 1)

As champions, they have been able to convince programme managers not to worry about negative evaluation findings but rather use the recommendations and lessons as to how they could strengthen the programme.

(Respondent 2)

Officials in the DBE also valued the facilitation of the DPME in driving and leading the evaluation system and providing technical advice as well as the presence of the NES, which emphasises evaluation quality and use.

\section{Barriers to use}

Outside these two specific evaluations, impediments have arisen in the application of improvement plans where proposed activities have negative political implications, are inconsistent with the law, too expensive to implement, impractical, lack management support or require policy amendment and therefore are not enforceable. To ensure implementation, the improvement plans also need to be better linked to operational plans because that is how individuals are held to account (Respondent 1). The incorporation of improvement plan activities in the department's annual performance and operational plans is important to ensure that they are budgeted for and therefore implemented.

Mohohlwane (2018) explains potential hesitation by managers in undertaking evaluations, associated with uncertainty of the value of evaluations, concerns about underperformance and repercussions. She gives an example:

A programme manager may be held accountable for the programme being evaluated, however, they may not have control of all the underlying 
processes due to complexities in the structure, resourcing and the scale of programmes. These complexities include concurrent functions between national departments as well as the national and provincial education departments; funding that is received directly from National Treasury or Provincial Treasury to nine different Provincial Education Departments but accounted for nationally; and the number of schools in a programme.

Writing about the Grade R evaluation, Samuels et al. (2015) argue that one should not be naïve about the incentives facing government when conducting evaluations, because the results can point to significant problems and low impacts.

In an environment where the media are likely to pick up on this and create negative press for the implementing department, this creates an incentive for government officials to resent an evaluation rather than embrace it so as to learn from it.

Samuels et al. (2015, p. 9)

These observations suggest that DPME will need to find ways to assist partnering departments in communicating findings to the public and in ensuring that the process is constructive. With the NSNP, the report was leaked and the main television station wanted to do a feature on it.

\section{Lessons for the country going forward}

\section{How did the context and intervention influence the use of evidence in DBE?}

The realist analysis discussed in Chapter 1 suggests that in different contexts, particular interventions will result in varying outcomes. In the context of evidence use, interventions include an evidence generation process (e.g. an evaluation), use interventions adopted to try and promote use (e.g. evaluation steering committee), which influence certain behavioural mechanisms (access to information, building trust, etc.) and result in certain use outcomes (how evidence influences policy and practice). Understanding which mechanisms work within which context can help us understand conditions that increase the likelihood of research utilisation and therefore place us better to reproduce these.

The context in this case included the need for significant reforms and outcomes in education after huge financial resources had been committed and there was a need to demonstrate effectiveness. Multiple stakeholders at national and provincial levels are involved in implementation of educational programmes but with some confusion in roles. There is a history of using evidence in education, and there was a significant evidence champion, the Chief Directorate: Strategic Planning, Research and Coordination with a history of using evidence to support policy making. This was supported by a National 
Evaluation System giving recognition to evaluation, and systems and support for implementation.

In terms of evidence generation, the department had internal capacity to generate evidence and used a variety of sources, including evaluations, research and administrative data.

We see a number of use interventions being applied, including knowledge brokering by the evidence champion Chief Directorate. This helped to identify areas to evaluate, and to maximise ownership of the findings and recommendations. The systems and technical support under the NES, with the focus on collaboration, contributed to ownership and learning through the process. The quality assurance systems were important in building the credibility of the evaluations, even where, as in NSNP, there was no budget to do as extensive a survey as the DBE would have liked. The improvement plan was an important step in trying to ensure use.

We see examples of these leading to building of awareness, agreement/ownership and trust in the findings and recommendations, and the institutionalisation of recommendations, which all help lead to individual, organisation and systems change. However, some managers remained sceptical and more institutionalisation of improvement plans in operational plans and departmental annual performance plans and budgets was needed.

We see a range of outcomes being achieved. In terms of individual change, in both processes we see stakeholders becoming committed to change, building their motivation to use the results of the evaluation, and use evaluation more generally. Organisationally, we see a developing capability in DBE with the Research, M\&E Directorate having significant expertise in evaluation and strongly motivated to use evaluation, and a range of organisational changes directly emanating from the two evaluations.

\section{The main lessons that emerge}

Some of the lessons that emerge are:

- Having the same leadership for a relatively long period of time provides stability, which allows time for evidence to be generated and used to drive change.

- $\quad$ Crises can provide an opportunity for use of evidence - and developing an evidence base can provide the ability to respond quickly with evidence when need arises.

- With the increase in research and evaluations commissioned by the department, continuing political will to support independent evaluation, information and data is critical.

- Having an internal unit as evidence champions. In DBE they worked hard to promote appreciation of evidence, and to act as knowledge brokers linking evidence generation and use by policy makers and programme managers. 
- $\quad$ Evidence was sometimes viewed negatively by programme managers and advocacy is required. The role of an internal champion is key in addressing this.

- The role of a national evaluation system and a national champion to drive, lead it and provide technical advice is necessary.

- The importance of an approach that supports involvement of stakeholders through the process, so that they own the product and process, for example, developing the theory of change with stakeholders, or recommendations developed in an iterative manner in a broader stakeholder validation workshop.

- The importance of perceived legitimacy of the messengers. In one evaluation, the choice of service provider was considered problematic as a renowned critic of government programmes was appointed in the competitive bidding process, possibly compromising the legitimacy of the results and findings.

\section{Conclusions}

The cases presented in this chapter are evaluations where the evidence and recommendations from the evaluations were used. Although there were reservations about evaluation initially, the knowledge broker role of the Chief Directorate was important in leading the use of evaluations. The constant need to reinforce the utility of the evaluations was a stumbling block but was overcome by consistently communicating the benefits. Both evaluations eventually strengthened the hand of the programme managers in reviewing and strengthening policy implementation, despite low levels of understanding about the need for evaluation by programme managers and initial reservations about the evaluations being public.

Overall, this chapter provides a picture of how a government department can undertake evaluations effectively, and the importance of an internal knowledge broker to champion and support this. It also shows the usefulness of a national evaluation system providing key elements that encourage use.

\section{Notes}

1 Final year of schooling.

2 For a history of the assessments, see Thulare (2018) and Nuga-Deliwe (2017).

\section{References}

Davids, M., Samuels, M-L., September, R., Moeng, T.L., Richter, L., Mabogoane, T.W., et al. 2015. The pilot evaluation for the National Evaluation System in South Africa - A diagnostic review of early childhood development. African Evaluation Journal, 3(1), Art. \#141, 7 pages. http://dx.doi.org/10.4102/aej.v3i1.141

DBE. 2009. National School Nutrition Programme (NSNP) 2009/10. Annual Report. Department of Basic Education.

DBE. 2010. Curriculum news. Department of Basic Education. Pretoria. 
DBE. 2018a, October. Teacher indaba evaluation report. Research Coordination, Monitoring \& Evaluation Directorate. Department of Basic Education.

DBE. 2018b. General Household Survey (GHS): Focus on Schooling 2017. Department of Basic Education.

DPME. 2014. Evaluation guideline 2.2.6. How to develop an improvement plan to address evaluation recommendations. Department of Planning, Monitoring and Evaluation.

DPME. 2017. Report on the assessment of government evaluations - Implementation evaluation of the national school nutrition programme. Department of Planning, Monitoring and Evaluation.

DPME/DBE. 2016a. Implementation evaluation of the national school nutrition programme: Evaluation report. Department of Planning, Monitoring and Evaluation, and Department of Basic Education.

DPME/DBE. 2016b. Implementation evaluation of the Funza Lushaka Bursary Programme: Evaluation report. Department of Planning, Monitoring and Evaluation, and Department of Basic Education.

Goldman, I., Mathe, J.E., Jacob, C., Hercules, A., Amisi, M., Buthelezi, T., et al. 2015. Developing South Africa's national evaluation policy and system: First lessons learned. African Evaluation Journal, 3(1), 107, 9 pages. http://dx.doi. org/10.4102/aej.v3i1.107

Johnson, K., Greenseid, L.O., Toal, S.A., King, J.A., Lawrenz, F. and Volkov, B. 2009. Research on evaluation use: A review of the empirical literature from 1986 to 2005. American Journal of Evaluation, 30, 377-410. https://doi.org/10.1177/1098214009341660

Mohohlwane, N. 2018. Implementing evaluations: Successes and challenges from a DBE perspective, available at: https://www.zenexfoundation.org.za/programme/thoughtleadership/m-e/item/363-implementing-evaluations-successes-and-challenges-from-adbe-perspective, accessed 15 March 2019

Motala, S. 2015. Equity, access and quality in basic education: A review. Journal of Education, 61.

National Planning Commission (NPC). 2012. National development plan 2030: Our futuremake it work. Pretoria: Presidency of South Africa.

National Planning Commission, Diagnostic Overview. 2011. Retrieved 20 September 2018, from www.nationalplanningcommission.org.za/Downloads/diagnosticoverview.pdf

Nuga Deliwe, C.O. 2017. An analysis of the measurement of the progress in learning outcomes at country level: the case of South Africa. University of Wits, South Africa http:// wiredspace.wits.ac.za/handle/10539/25944

OECD. 2008. Reviews of national policies for education: South Africa. Reviews of National Policies for Education, OECD Publishing, Paris, https://doi.org/10.1787/9789264053526-en.

Patton, M.Q. 1998. Discovering process use. Evaluation, 4, 225-233. https://doi.org/10. $1177 / 13563899822208437$

Phillips, S., Goldman, I., Gasa, N., Akhalwaya, I. and Leon, B. 2014. A focus on M\&E of results: An example from the Presidency, South Africa. Journal of Development Effectiveness, 6, 392-406. https://doi.org/10.1080/19439342.2014.966453

Reddy,V.,Visser, M., Winnaar, L., Arends, F., Juan, A. and Prinsloo, C.H. 2016. TIMSS 2015: Highlights of mathematics and science achievement of grade 9 South African learners. Pretoria: Human Sciences Research Council.

Samuels, M., Taylor, S., Shepherd, D., Van der Berg, S., Jacob, C., Deliwe, C.N., et al. 2015. Reflecting on an impact evaluation of the Grade $\mathrm{R}$ programme: Method, results and policy responses. African Evaluation Journal, 3b(1), Art. \#139, 10 pages. http://dx.doi. org/10.4102/aej.v3i1.139

Thulare, T.D. 2018. A policy analysis of the annual national assessments in South Africa. In Wiseman, A.W. and Davidson, P.M. (eds.), Cross-nationally comparative, evidence-based educational policymaking and reform Emerald Publishing Limited, pp. 71-100. https://doi. org/10.1108/S1479-367920180000035004 